\title{
Correction to: The pleasure of multiple images
}

\author{
Aenne A. Brielmann ${ }^{1,2}$ (D) Denis G. Pelli ${ }^{1,3}$ \\ Published online: 9 December 2020 \\ (C) The Psychonomic Society, Inc. 2020
}

\section{Correction to: Atten Percept Psychophys https://doi.org/10.3758/s13414-020-02175-Z}

One of the author's proof corrections was not carried out by the typesetter.

In equation 4 in the inline equation, $\mathrm{P}$ and P-bar are mistakenly swapped. The $\mathrm{P}$ on the left side of the equal sign should be P-bar, NOT the $\mathrm{P}$ in the nominator on the right side.

The same inline equation appears correctly above, immediately after Eq. 2.

The original article has been corrected.

Publisher's note Springer Nature remains neutral with regard to jurisdictional claims in published maps and institutional affiliations.

The online version of the original article can be found at https://doi.org/ $10.3758 / \mathrm{s} 13414-020-02175-\mathrm{Z}$

$\triangle$ Aenne A. Brielmann aenne.brielmann@tuebingen.mpg.de

1 Psychology Department, New York University, New York, NY, USA

2 Max Planck Institute for Biological Cybernetics, Tübingen, Germany

3 Center for Neural Science, New York University, New York, NY, USA 